\title{
INVESTIGATION OF THE MICROSTRUCTURE AND PROPERTIES OF THE AISI H13 TOOL STEEL TI-MODIFIED POWDER DURING LASER CLADDING PROCESS UNDER NITROGEN
}

\author{
1Dmitriy MASAYLO, ${ }^{2}$ Sergei IGOSHIN, ${ }^{3}$ Anatoliy POPOVICH \\ Peter the Great St. Petersburg Polytechnic University, St. Petersburg, Russia, \\ 1'dmasaylo@gmail.com, ${ }^{2}$ sergei.igosshin@gmail.com, ${ }^{3}$ popovicha@mail.ru
}

https://doi.org/10.37904/metal.2021.4132

\begin{abstract}
Laser cladding (LC) technology allows produce metal-matrix composites from discrete powder materials. Data analysis shows that use of such technology to obtain composite materials with enhanced functional properties is of heightened economical interest. The paper presents the results of research aimed at study the possibility synthesizing dispersion-strengthened steel by hard TiN particles formed during the interaction of elemental $\mathrm{Ti}$ powder with $\mathrm{N}_{2}$ gas. It is added $5 \%$ of VT1-0 titanium powder to the AISI H13 tool steel to form a mechanical mixture. Specimen was synthesized from this mixture on a substrate by laser cladding under nitrogen. Owing to the optical and electron microscopy, X-ray phase analysis as well as microhardness testing it was determined that as a result of synthesis, an alloy of steel with Ti with a lower hardness value is formed compared to the $\mathrm{H} 13$ steel deposited in pure form. Uniformly distributed nonmetallic inclusions were found, including titanium nitride in the form of dispersed particles. Thus, it can be concluded that before the titanium powder enters the melt pool, there is not enough temperature and time for diffusion processes with the formation of non-melting TiN particles in the steel matrix. Therefore, this phase is formed from the melt during crystallization. As a result, the high titanium in the form of an alloying element in steel does not lead to the targeted formation of a hardened metal-matrix composite but increases the plastic properties and reduces the quality of track formation during process.
\end{abstract}

Keywords: Laser cladding, direct laser deposition, alloy synthesis, titanium nitriding, microstructure.

\section{INTRODUCTION}

Laser cladding (LC), as well as its more modern direction, which implements the principle of additive technologies - direct laser deposition (DLD), has great potential in the field of synthesis of classical materials and new materials. Laser technologies for metal deposition have the advantage of precise local heating with a wide range of adjustable heating zones with a laser spot diameter from 0.5 to $5 \mathrm{~mm}$, laser power from 100 to $10000 \mathrm{~W}$, laser wavelength $500-1200 \mathrm{~nm}$ for different types of materials, also modes work with continuous or pulse processing. The main purpose of this technology is the cladding of functional coatings, repair, and additive building of new parts with a strong metal bond of materials and a reduced heating temperature of the substrate. To date, extensive knowledge has been accumulated on the properties of various widely used alloys obtained by these technologies. Scientific papers on the following popular alloys are publicly available: $\mathrm{H} 13$ steel, 316L and 304 steel, Ti-6Al-4V titanium alloy, Inconel 625 and 718 nickel alloy [1-4]. The current trends in the development of new materials by this method indicate a high potential for using laser technologies for this purpose. A huge range of rare and less popular alloys that can also be obtained by LC and DLD methods, for example, high-entropy alloys [5], which in terms of hardness, heat resistance, heat resistance, corrosion resistance, wear resistance can compete with traditional special-purpose alloys, shape memory-based alloys, for example, NiTi [6], alloys with dispersion hardening by solid particles, for example, WC for obtaining wearresistant materials [7]. 
The aim of the work was to create a dispersion-hardened alloy using the example of steel $\mathrm{H} 13$ with a stable solid phase from TiN inclusions. Dispersion-hardened materials are those whose resistance to plastic deformation is determined by the deceleration of dislocations on obstacles in the form, as a rule, of nanosized particles. Such structures are obtained in various ways - by separating nanoparticles from a supersaturated solid solution (precipitation-hardening alloys), by powder metallurgy, including mechanical alloying, by internal oxidation and nitriding. The material of the particle is chosen from the most stable compounds - oxides, carbides, nitrides.

The interaction of Ti powder mixed with a die maraging steel $\mathrm{H} 13$ in a nitrogen atmosphere in an amount of 5 $\%$ in wt is investigated. That is, the effect of nitrogen on the formation of the alloy in the presence of the active element titanium in its pure form is evaluated.

\section{METHODOLOGY AND EXPERIMENT}

To form the H13/Ti mixture, AISI H13 steel powder produced by TLS Technik in the delivery state and VT-1 0 titanium powder produced by «Normin» were used. The technical characteristics and appearance of the powders are presented in Table 1. The raw powder materials were mixed mechanically in a gravity mill for 4 hours. The ratio of powders in the mixture is $95 \% \mathrm{H} 13-5 \% \mathrm{Ti}$ (in wt\%). The finished mechanical mixture was loaded into the DLD powder feeder. The cladding was carried out on a low-alloy steel substrate with a thickness of $5 \mathrm{~mm}$. Instead of argon, high-purity nitrogen gas was used to supply the powder to the melting zone in the form of a gas-powder mixture and to locally protect the melting zone.

Table 1 Powders for mixing $\mathrm{H} 13 / \mathrm{Ti}$

\begin{tabular}{|c|c|c|c|}
\hline Powder & Particle size, $\mu \mathrm{m}$ & Particle shape & Chemical composition (w.\%) \\
\hline AISI H13 & $45-90$ & & $\begin{array}{c}\mathrm{Fe}-\text { bal., } \mathrm{C}-0.4, \mathrm{Si}-1.0, \mathrm{Mn}-0.48, \mathrm{Cr}-5.3, \mathrm{Mo}- \\
1.3, \mathrm{~V}-1.0\end{array}$ \\
\hline $\mathrm{Ti}(\mathrm{VT}-10)$ & $45-100$ & & $\begin{array}{c}\mathrm{Ti}-\text { bal., } \mathrm{Al}-0.3, \mathrm{Si}-0.01, \mathrm{Fe}-0.15, \mathrm{O}-0.15, \mathrm{~N}- \\
0.02, \mathrm{C}-0.021\end{array}$ \\
\hline
\end{tabular}

The laboratory setup for laser cladding, which was used for the experiment, consists of the following components: ytterbium fiber laser iPG LS-3, powder feeder PF 2/2, optical system (cladding head) KUKA MWO-1 and Fanuc M20i robot.

LC was used to build thick-walled samples with a height of $10 \mathrm{~mm}$ from a powder mixture of H13-5Ti. Two laser powers were used in the experiment: a reduced power of $1100 \mathrm{~W}$ and an increased power of $1400 \mathrm{~W}$. All other technological parameters were fixed, and they are indicated in Table 2 . The samples were cut, and metallographic sections were made from them in two directions: parallel $(X Y)$ and perpendicular $(X Z)$ to the growing direction. Chemical etching of metallographic sections was carried out in a solution of $10 \mathrm{ml} \mathrm{HNO} 3,30$ $\mathrm{ml} \mathrm{HCl}$ and $40 \mathrm{ml} \mathrm{H}_{2} \mathrm{O}$. Photos of the microstructure were obtained using a Leica optical microscope. Chemical analysis was carried out on SEM Tescan Mira 3 electron microscope with EDS attachment. X-ray phase analysis was carried out on Bruker D8 Advance diffractometer. Quantitative phase analysis was performed using TOPAS5 software. 
Table 2 DLD parameters for growing samples from elementary powders from $\mathrm{H} 13-5 \mathrm{Ti}$ mixture in nitrogen atmosphere.

\begin{tabular}{|c|c|}
\hline Cladding parameter & Parameter value \\
\hline Speed of movement & $10 \mathrm{~mm} / \mathrm{s}$ \\
\hline Powder feed & $15 \mathrm{~g} / \mathrm{min}$ \\
\hline Shielding gas-nitrogen & $15 \mathrm{l} / \mathrm{min}$ \\
\hline Transportation gas-nitrogen & $6 \mathrm{l} / \mathrm{min}$ \\
\hline Laser power & 1100 and $1400 \mathrm{~W}$ \\
\hline Lifting height & $0.6 \mathrm{~mm}$ \\
\hline Offset & $50 \%$ \\
\hline Laser spot size & $3 \mathrm{~mm}$ \\
\hline
\end{tabular}

\section{RESULT AND DISCUSSION}

As a result of the experiment, two thin-walled samples were obtained from a mixture of H13-5Ti (Figure 1).

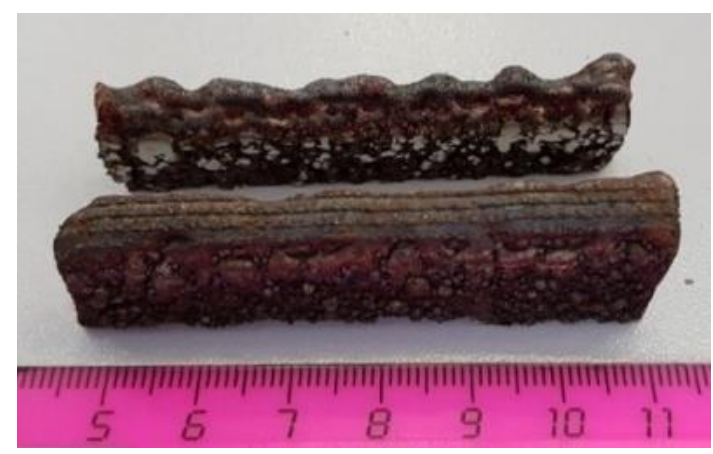

Figure 1 Thin-walled samples grown from a powder mixture of $\mathrm{H} 13-5 \mathrm{Ti}$ in a nitrogen atmosphere at a laser power of $1100 \mathrm{~W}$ (front sample), of $1400 \mathrm{~W}$ (back sample).

SEM photos of the non-etched structure showed the presence of inclusions evenly distributed over the entire volume of the material. The inclusions in the sample grown at a power of $1100 \mathrm{~W}$ are evenly distributed in the matrix of the base material and their size does not exceed $1 \mu \mathrm{m}$. In the sample grown at a power of $1400 \mathrm{~W}$, there are larger phases of 1-2 microns. The image of the microstructure is shown in Figure 2. Some inclusions have a square shape characteristic of TiN nitrides, and the formation of $\mathrm{TiC}_{\mathrm{x}} \mathrm{N}_{\mathrm{y}}$ carbonitrides is also possible under experimental conditions, but only titanium nitrides were determined by the XRD result. Authors of the work [8] report that micron-sized TiN emissions contribute to the mechanism of steel failure by acting as sites of voids or cracks. However, in this case, their role in the destruction mechanism was reported only for micro-sized TiN secretions [9]. It was reported that cubic or rectangular secretions with sizes from 3 to $90 \mathrm{~nm}$ are more effective than spherical secretions in terms of grain growth retardation and increased strength characteristics. Therefore, it can be concluded that the target state of titanium nitride inclusions in steel should be nanoscale particles.

a)

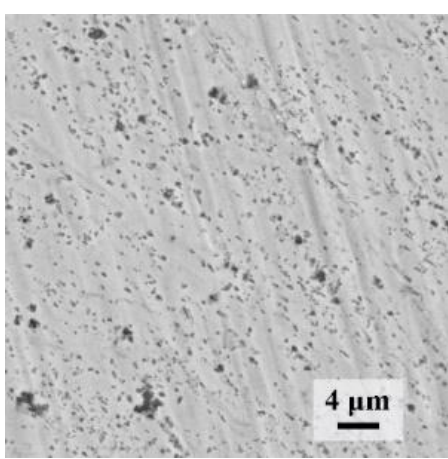

b)

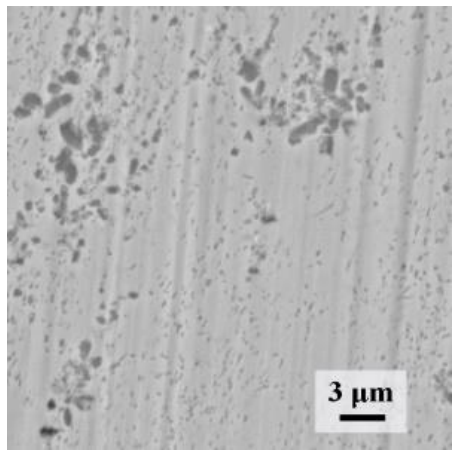

Figure 2 SEM images of a thin-walled sample in the $X Z$ direction, where a is a sample at a laser power of $1100 \mathrm{~W}, \mathrm{~b}$ is a sample at a laser power of $1400 \mathrm{~W}$ 


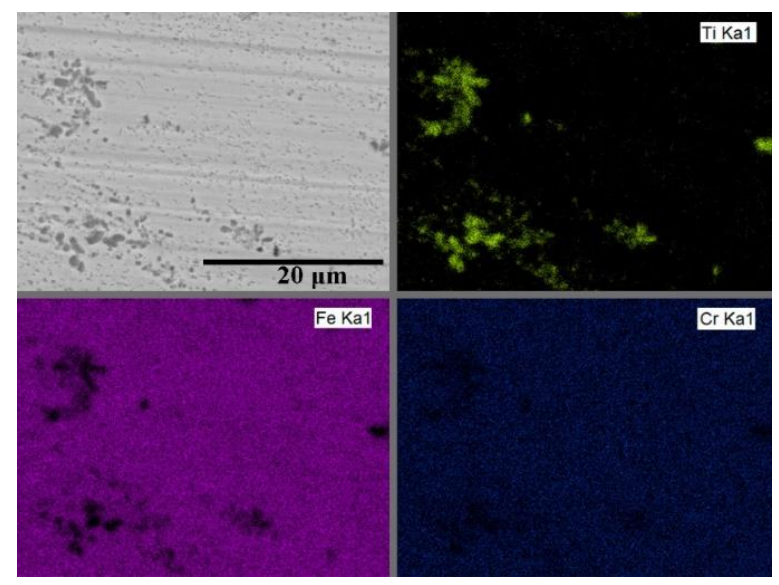

Figure 3 Map of the distribution of elements in the synthesized sample

The distribution of chemical elements in the sample was obtained by the EDS method. Figure 3 shows that the main component of the inclusions is titanium. The total chemical composition of the material is shown in Table 3.

Table 3 Chemical composition of samples obtained by laser cladding from a mixture of H13-5Ti

\begin{tabular}{|c|c|c|c|c|c|c|}
\hline Element & Si K & TiK & V K & Cr K & Fe K & Mo L \\
\hline Weight \% & 1.08 & 4.88 & 1.11 & 5.42 & 85.70 & 1.82 \\
\hline Atomic \% & 2.11 & 5.60 & 1.19 & 5.73 & 84.33 & 1.04 \\
\hline
\end{tabular}

The microstructure of the etched samples, which is shown in Figure 4, has no significant differences when changing the laser power or the direction of the study. The structure in the $X Y$ and $X Z$ directions also does not differ, which is an interesting result, since the typical structure of the sample obtained by the PLV method has a pronounced texture corresponding to the direction of grain growth towards the heating source, usually at the $\mathrm{Z}$ coordinate (up).

a)

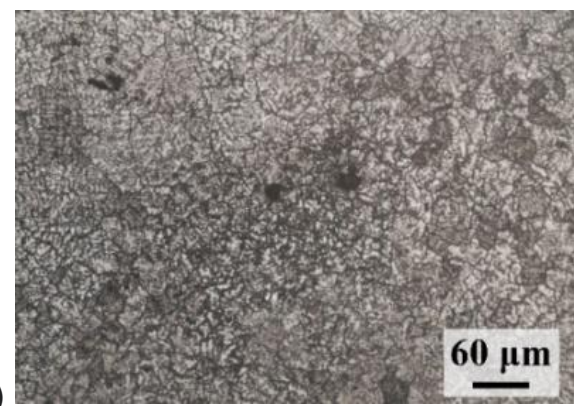

c)

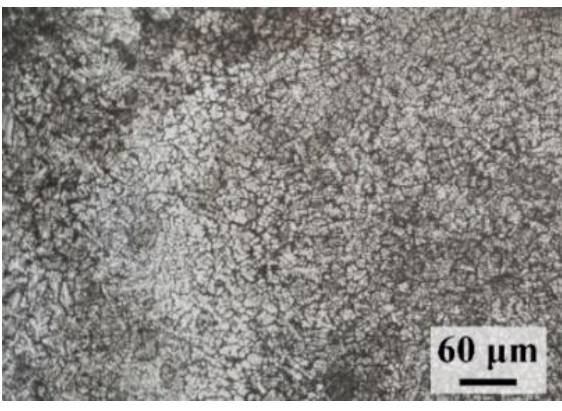

b)

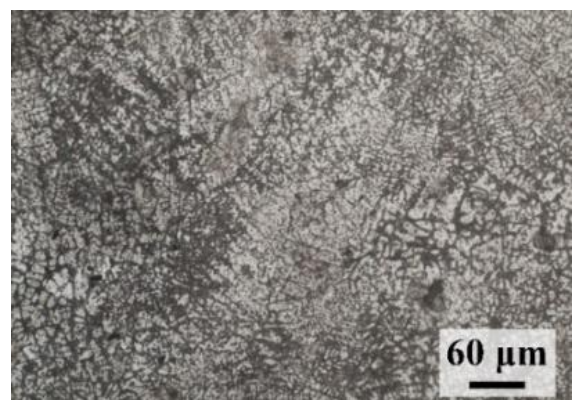

d)

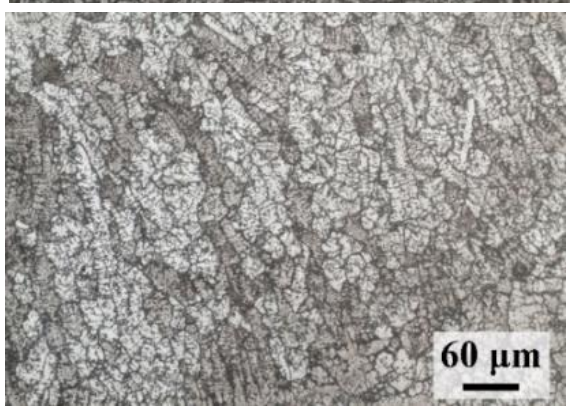

Figure 4 Microstructure of thin-walled samples in an optical microscope at x200 magnification, where a $1100 \mathrm{~W}, \mathrm{XY}$ direction, $\mathrm{b}-1100 \mathrm{~W}, \mathrm{XZ}$ direction, $\mathrm{c}-1400 \mathrm{~W}, \mathrm{XY}$ direction, $\mathrm{d}-1400 \mathrm{~W}, \mathrm{XZ}$ direction 
The microstructure of the sample consists of equiaxed dendrites of the first and second order without a pronounced orientation of the growth direction. There are also areas with a grainy structure in the photographs. The average size of the structural components for a sample grown at a laser power of $1100 \mathrm{~W}$ is $5-10 \mu \mathrm{m}$; with an increase in the laser power to $1400 \mathrm{~W}$, the size of the structural components increased to $30 \mu \mathrm{m}$. This type of mixed structure and its size is typical of $\mathrm{H} 13$ steel obtained by direct laser deposition [10]. Often the structure of this steel obtained by the DLD method has the same (but several components) structure within a single track [1]. Additional mechanical alloying of titanium powder with elemental elements significantly reduced the homogeneity of the structure of steel $\mathrm{H} 13$ within each individual track due to high cooling rates during additive building. This effect does not allow the full extent of diffusion mixing processes. For the same reason, there is no clear boundary between each single track.

a)

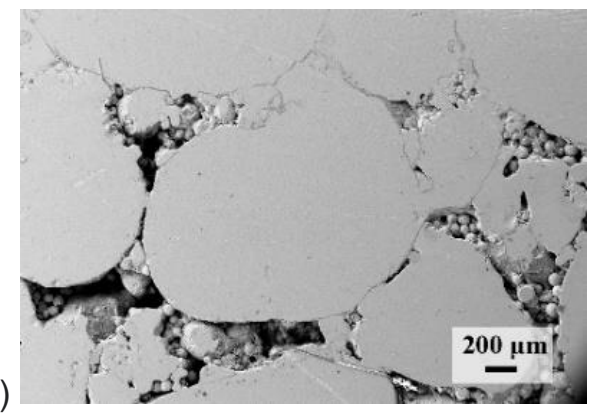

b)

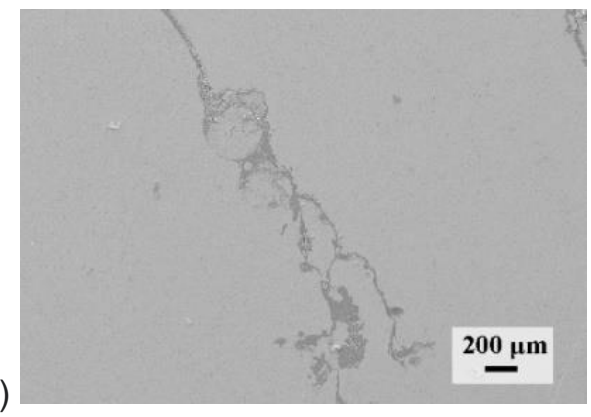

Figure 5 Emerging defects during thin-walled sample building: pores with unmelted powder, and longrange boundary inclusions

The addition of titanium powder to steel $\mathrm{H} 13$, as well as a nitrogen atmosphere, significantly reduced the quality of multilayer samples under the same technological conditions that are used for this steel. Defects uncharacteristic for the $\mathrm{H} 13$ alloy were found - unmelted powder, pores, and boundary inclusions of a large extent (Figure 5). Since LC occurred only with local protection of the melting zone, titanium could form phases with oxygen in the air. To make sure that the nitride inclusions were formed, an $\mathrm{XRD}$ analysis was performed (Figure 6), since the EDS analysis cannot determine the nitrogen content. The analysis showed that in addition to the main phase of $\alpha-F e$, there is a small reflex in the region of 410 , which is probably associated with the presence of a small amount of $\mathrm{TiN}$ with the $\mathrm{HCC}$ structure. The TiN phase was detected in the sample obtained at a power of 1400 $\mathrm{W}$, and this phase was not observed on the diffractogram at $1100 \mathrm{~W}$, probably due to its low

a)
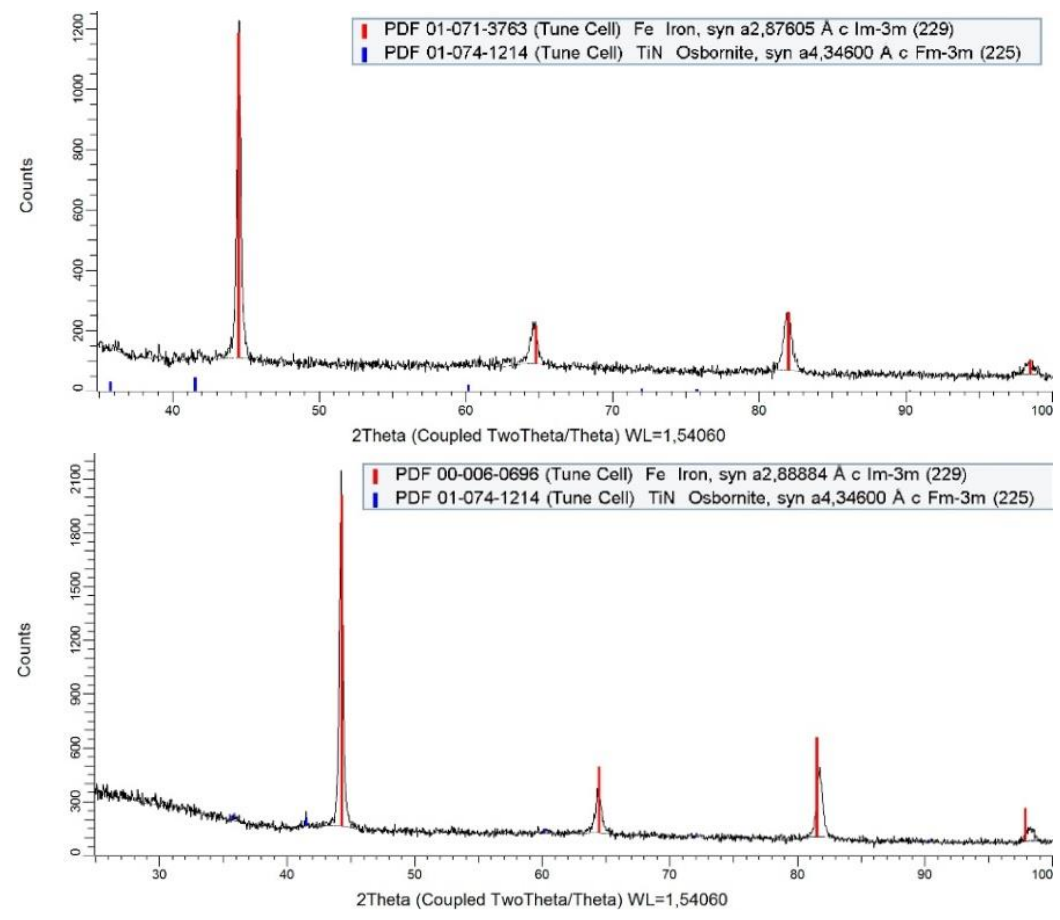

Figure 6 XRD of thick-walled samples, a-1100 W, b-1400 W content. 
Typical hardness of H13 steel obtained by LC or DLD for single tracks is $400-650 \mathrm{HV}$ [11], 500-800 HV [Wolosz2020] and for multi-layer coatings 500-650 HV [12]. Since the introduction of a large amount of titanium in carbon alloy steel reduces the hardness and strength characteristics. Since, in addition to the formation of nitrides, titanium binds carbon into resistant carbides, which do not participate in the processes of dispersion hardening.

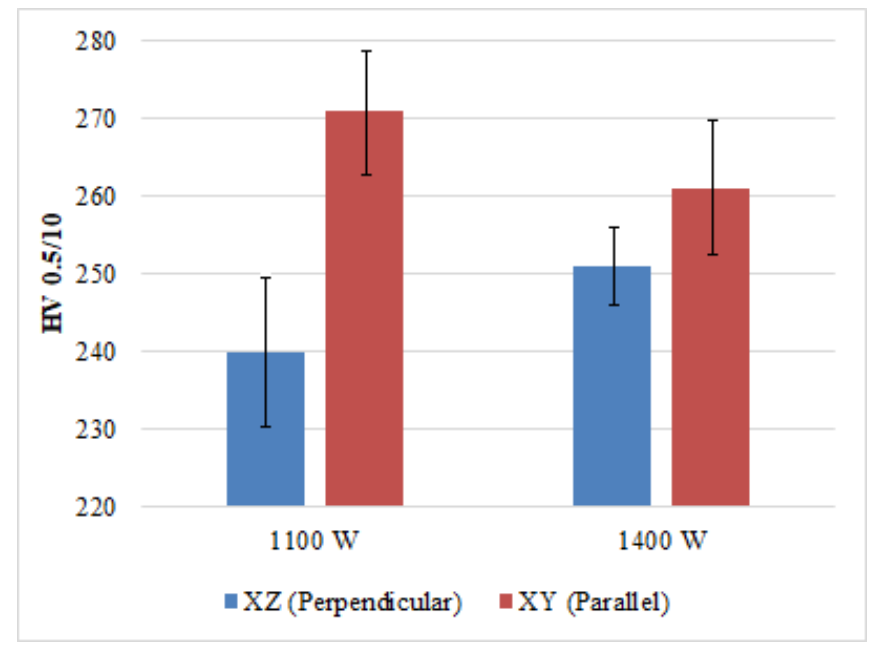

Figure 7 Influence of laser power on specimen hardness in two directions

Figure 7 shows the results of the hardness values in the $X Z$ and $X Y$ directions, which indicate a significant decrease in this characteristic compared to a material without the addition of titanium. The change in the laser power mainly affected the difference in hardness in two different directions. With an increase in the laser power, the cooling time of the deposited track correspondingly increases, which reduces thermal stresses inside the material, which affect the hardness.

\section{CONCLUSION}

The main result of the work is that during the synthesis of an alloy from a mechanical mixture of steel $\mathrm{H} 13$ and titanium powder in a nitrogen atmosphere, titanium nitrides are formed. TiN inclusions are formed from the liquid phase after the powder mixture is remelted in a molten bath and titanium is bonded with nitrogen at a high temperature. The size of the inclusions, predominantly located along the grain boundaries in the steel matrix, is 1-2 $\mu \mathrm{m}$. Mechanical properties, namely the hardness of the samples, significantly decreased and amounts to $240-280 \mathrm{HV}$, depending on the direction of research and laser power. The results of the work show the possibility of practical application of the nitriding method in the process of laser cladding and direct laser growth with the formation of dispersion-hardening particles.

\section{ACKNOWLEDGEMENTS}

We acknowledge the support from Russian Science Foundation grant (project №. 19-79-30002).

\section{REFERENCES}

[1] WOŁOSZ P., BARAN A., POLAŃSKI M. The influence of laser engineered net shaping (LENSTM) technological parameters on the laser deposition efficiency and properties of H13 (AISI) steel. J. Alloys Compd. 2020, vol. 823, p. 153840.

[2] WU X. et al. Microstructures of laser-deposited Ti-6Al-4V. Mater. Des. 2004, vol. 25, no. 2, pp. 137-144.

[3] GORUNOV A.I. Directional Crystallization of 316L Stainless Steel Specimens by Direct Laser Deposition. Inorg. Mater. 2019. vol. 55, no. 15, pp. 1439-1444. 
[4] MASAYLO D. et al. Laser cladding nickel based superalloy inconel 625. In: METAL 2018 - 27th International Conference on Metallurgy and Materials, Conference Proceedings. Brno: Tanger, 2018, pp. 1618-1625.

[5] RAZUMOV N. et al. Refractory CrMoNbWV High-Entropy Alloy Manufactured by Mechanical Alloying and Spark Plasma Sintering: Evolution of Microstructure and Properties. Materials (Basel). 2021, vol. 14, no. 3, p. 621.

[6] ELAHINIA M. et al. Fabrication of NiTi through additive manufacturing: A review. Prog. Mater. Sci. 2016, vol. 83, pp. 630-663.

[7] ZHONG M. et al. Formation of WC/Ni hard alloy coating by laser cladding of W/C/Ni pure element powder blend. Int. J. Refract. Met. Hard Mater. 2006, vol. 24, no. 6, pp. 453-460.

[8] LEE T.-W. et al. Microstructural characterization and thermodynamic analysis of precipitates in ultra-low-carbon bake hardened steel. J. Alloys Compd. 2014, vol. 582, pp. 428-436.

[9] LIU S., LIAO F.-C. Precipitate stability in the heat affected zone of nitrogen-enhanced high strength low alloy steels. Mater. Sci. Eng. A. 1998, vol. 244, no. 2, pp. 273-283.

[10] PARK J.S. et al. Effect of Energy Input on the Characteristic of AISI H13 and D2 Tool Steels Deposited by a Directed Energy Deposition Process. Metall. Mater. Trans. A Phys. Metall. Mater. Sci. Springer US. 2016, vol. 47, no. 5, pp. 2529-2535.

[11] BAILEY N.S., KATINAS C., SHIN Y.C. Laser direct deposition of AISI H13 tool steel powder with numerical modeling of solid phase transformation, hardness, and residual stresses. J. Mater. Process. Technol. 2017, vol. 247, pp. 223-233.

[12] IGOSHIN S. et al. Features of the recovery of high carbon steel products using the Directed Energy Deposition process. 2019, pp. 685-690. 